\title{
Combination therapy of hypertension in the elderly: a subgroup analysis of the Combination of OLMesartan and a calcium channel blocker or diuretic in Japanese elderly hypertensive patients trial
}

\author{
Toshio Ogihara ${ }^{1}$, Takao Saruta ${ }^{2}$, Hiromi Rakugi ${ }^{3}$, Ikuo Saito ${ }^{2}$, Kazuaki Shimamoto ${ }^{4}$, Hiroaki Matsuoka ${ }^{5}$, \\ Satoshi Teramukai ${ }^{6}$, Jitsuo Higaki ${ }^{7}$, Sadayoshi Ito ${ }^{8}$ and Kazuyuki Shimada ${ }^{9}$ for the COLM investigators
}

Combination of OLMesartan and a calcium channel blocker or a diuretic in Japanese elderly hypertensive patients (COLM) trial demonstrated that olmesartan combinations with a CCB or diuretic have similar effects on reducing cardiovascular risk in elderly hypertensive patients. However, the safety profiles suggest that olmesartan combined with CCB may be preferable to olmesartan combined with diuretic. In this subgroup analysis, we further evaluated the effects and safety of these combinations in elderly (65-74 years old (y.o.)) and very elderly (75-84 y.o.) hypertensive patients. In the COLM trial, 5141 patients (2918 elderly and 2223 very elderly) were randomly assigned to receive olmesartan-based therapy with either CCB or diuretic. The hazard ratios and $95 \%$ confidence intervals, respectively, in the elderly age group and in the very elderly group were: $1.04(0.72-1.50$; olmesartan plus CCB vs. olmesartan plus diuretic, $P=0.85)$ and $0.71(0.51-0.99, P=0.045)$ for the primary composite end point, and $1.07(0.67-1.72, P=0.77)$ and $0.64(0.42-0.98, P=0.036)$ for the composite of hard end points. The hazard ratios for stroke (fatal and non-fatal) were $1.48(0.88-2.48$; olmesartan plus CCB vs. olmesartan plus diuretic, $P=0.13)$ and $0.63(0.39-1.02, P=0.059)$ (interaction- $P=0.019$ ). Withdrawal rates from the trial, withdrawal due to serious adverse event and the incidence of any adverse event were higher in the olmesartan plus diuretic group than in the olmesartan plus CCB group in both age groups. In conclusion, angiotensin receptor blocker (ARB) and CCB combination may be preferable to an ARB and diuretic combination in the very elderly hypertensive patients for the reduction of cardiovascular risk, particularly for the reduction in stroke risk.

Hypertension Research (2015) 38, 89-96; doi:10.1038/hr.2014.144; published online 25 September 2014

Keywords: calcium channel blocker; combination therapy; diuretic; elderly hypertension; olmesartan

\section{INTRODUCTION}

Antihypertensive treatment reduces cardiovascular morbidity and mortality in elderly patients with hypertension as well as in patients in other age groups. Recently, the Hypertension in the Very Elderly Trial (HYVET) has shown that a diuretic and an angiotensinconverting enzyme inhibitor as add-on treatment reduced cardiovascular mortality in hypertensive patients aged 80 years and older. ${ }^{1}$ It is well known that the majority of hypertensive patients will require at least two antihypertensive drugs to achieve target blood pressure (BP); thus, combination therapy of two antihypertensive drugs has been recommended in guidelines for management of hypertension ${ }^{2-4}$ and is very common in general practice. However, there are few clinical trials to evaluate the optimal combinations of antihypertensive drugs. ${ }^{5,6}$
Combination of OLMesartan and a calcium channel blocker or a diuretic in Japanese elderly hypertensive patients (COLM) trial was a prospective, randomized, open-label, blinded end oint (PROBE) study to determine which combination is the preferable therapy for hypertension: angiotensin receptor blocker (ARB) plus calcium channel blocker (CCB) or ARB plus diuretic. ${ }^{7,8}$ The principal results have demonstrated that there were no remarkable differences in the primary composite end points of cardiovascular morbidity and mortality between the two groups, olmesartan plus CCB and olmesartan plus diuretic. ${ }^{8}$ However, safety and tolerability profiles suggested that olmesartan plus CCB may be preferable to olmesartan plus diuretic. ${ }^{8}$ A prespecified subgroup analysis showed that the incidence of stroke was higher in the olmesartan plus diuretic group

${ }^{1}$ Morinomiya University of Medical Sciences, Osaka, Japan; ${ }^{2}$ Keio University, Tokyo, Japan; ${ }^{3}$ Osaka University Graduate School of Medicine, Osaka, Japan; ${ }^{4}$ Sapporo Medical University, Sapporo, Japan; ${ }^{5}$ Dokkyo Medical University, Mibu, Japan; ${ }^{6}$ Kyoto Prefectural University of Medicine Graduate School of Medical Science, Kyoto, Japan; ${ }^{7}$ Ehime University Graduate School of Medicine, Ehime, Japan; ${ }^{8}$ Tohoku University Graduate School of Medicine, Sendai, Japan and ${ }^{9}$ Shin-oyama City Hospital, Oyama, Japan Correspondence: Professor T Ogihara, Morinomiya University of Medical Sciences, 1-26-16 Nankokita, Suminoe-ku, Osaka 559-8611, Japan.

E-mail: ogihara@morinomiya-u.ac.jp

Received 27 May 2014; revised 28 July 2014; accepted 5 August 2014; published online 25 September 2014 
than in the olmesartan plus CCB group in elderly patients aged 75 years and older. ${ }^{8}$

In this report, we further describe this prespecified subgroup analysis of the COLM trial according to age to elucidate which combination is desirable in elderly patients, particularly those aged 75 years and older.

\section{METHODS}

The COLM trial was an investigator-initiated multicenter study with PROBE design that compared cardiovascular effects of two regimens: an angiotensin II antagonist (ARB, olmesartan) plus a dihydropyridine $\mathrm{CCB}$ or a diuretic in highrisk elderly Japanese hypertensive patients. The rationale, design, trial management and the principal results of the COLM trial have already been reported. ${ }^{7,8}$

In brief, hypertensive patients aged 65-84 years with a history of cardiovascular disease and/or cardiovascular risk factors whose systolic BP was $\geqslant 140$ $\mathrm{mm} \mathrm{Hg}$ and/or whose diastolic BP was $\geqslant 90 \mathrm{~mm} \mathrm{Hg}$ with antihypertensive treatment or $\mathrm{BP} \geqslant 160$ and/or $100 \mathrm{~mm} \mathrm{Hg}$ without treatment were randomized to receive olmesartan with either a CCB (amlodipine or azelnidipine) or a lowdose diuretic (trichlomethiazide, indapamide or other thiazide) for at least 3 years. The target BP was $<140 / 90 \mathrm{~mm} \mathrm{Hg}$. The median follow-up time was 3.3 years. $^{8}$

The trial was conducted in accordance with the Declaration of Helsinki. The protocol was reviewed and approved by institutional review boards at each participating center. The trial was conducted between April 2007 and September 2011 at 707 primary care and cardiology centers in Japan. ${ }^{8}$

A prespecified subgroup analysis was made to compare the cardiovascular effects and safety of ARB-based combination regimens (olmesartan plus CCB vs. olmesartan plus diuretic) in patients who are 65-74 years old (y.o.) (the elderly age group) and those aged $75-84$ years (the very elderly age group). The evaluated end points were consistent with the original trial design and included the primary and secondary end points of the COLM trial; ;,8 primary end point included a composite of cardiovascular morbidity and mortality (sudden death, fatal or non-fatal stroke including transient ischemic attack, fatal or non-fatal myocardial infarction, coronary revascularization, hospitalization for angina pectoris or heart failure and renal events); secondary end points included each component of the primary end point, all-cause mortality, hard composite cardiovascular events (cardiovascular death, non-fatal myocardial infarction and non-fatal stroke excluding transient ischemic attack), new onset of diabetes, new onset of atrial fibrillation, adverse events and withdrawal from the allocated treatment. Adverse events were classified as drug-related or nondrug-related and serious or non-serious and were monitored throughout the trial. All cardiovascular events and serious adverse events (SAEs) reported by the participating physicians were adjudicated by the endpoint committee, which was blinded to the study group. ${ }^{7,8}$

In total, 5141 patients (olmesartan plus CCB: 2568; and olmesartan plus diuretic: 2573) who were prescribed a combination treatment were categorized into the two groups (65-74 vs. 75-84 y.o.) and subjected to a full set analysis to evaluate specifically olmesartan-based combination therapy. Patient characteristics were reported as the mean \pm s.d. or percentage.

\section{Statistical analysis}

Student's $t$-test and the analysis of covariance adjusted by baseline data were used to compare the change in BP and heart rate between two treatment groups. Time-to-event curves were estimated with the Kaplan-Meier method for the primary cardiovascular composite end point and secondary end points among the two treatment groups in each age group. The stratified log-rank test was used to compare the incidence of these end points between the two groups using sex and history of cardiovascular diseases as stratification variables. To examine interactions between treatment groups and age groups and to estimate the hazard ratio (HR) and $95 \%$ confidence interval in each age group, the stratified proportional hazards model was used with sex and history of cardiovascular diseases as stratification variables. The fraction of patients with adverse events in each group was compared using Fisher's exact test. All statistical analyses were conducted using SAS 9.1 (SAS Institute, Cary, NC, USA).

\section{RESULTS}

The flow chart of the present subgroup analysis of the COLM trial and demographic characteristics of the patients are shown in Figure 1 and Table 1. Among the 5141 patients in the COLM trial, 2918 patients (56.8\%) were in the elderly age group and 2223 patients (43.2\%) were in the very elderly group. In both age groups, baseline characteristics were similar between the two combination groups with some exceptions such as dyslipidemia in the very elderly age group.

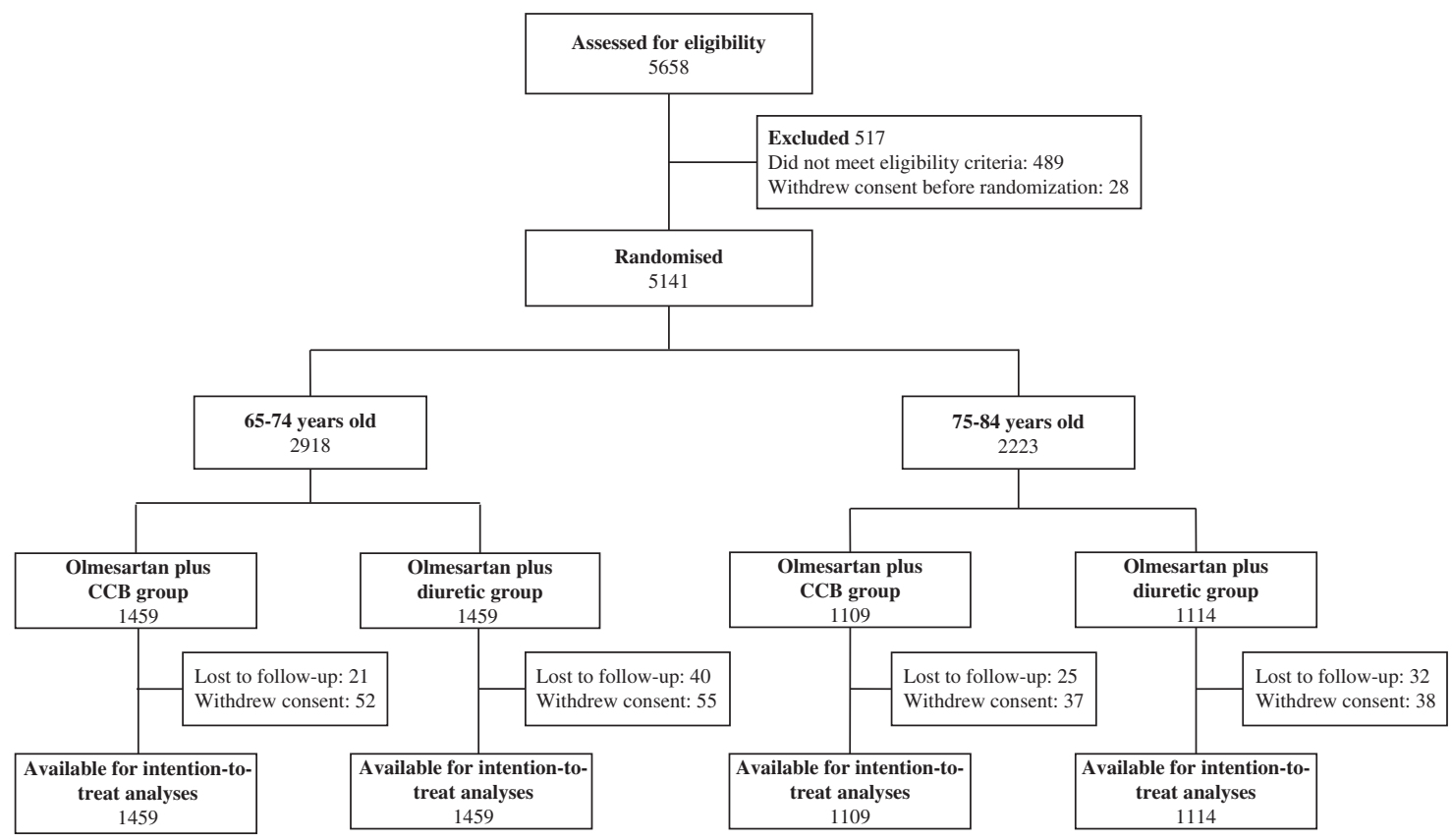

Figure 1 Patient disposition. 
Table 1 Demographic and baseline characteristics of the study patients

\begin{tabular}{|c|c|c|c|c|c|c|c|}
\hline \multirow{4}{*}{ Characteristic } & \multicolumn{6}{|c|}{ Age group (y.o.) } & \multirow{4}{*}{$\begin{array}{c}\text { 65-74 vs. } \\
75-84 \\
\text { P-value }\end{array}$} \\
\hline & \multicolumn{3}{|c|}{$65-74(n=2918)$} & \multicolumn{3}{|c|}{$75-84(n=2223)$} & \\
\hline & \multicolumn{6}{|c|}{ Subgroup } & \\
\hline & $\begin{array}{l}\text { Olmesartan plus CCB } \\
\qquad\left(\mathrm{n}=1459^{*}\right)\end{array}$ & $\begin{array}{l}\text { Olmesartan plus diuretic } \\
\qquad\left(\mathrm{n}=1459^{*}\right)\end{array}$ & P-value & $\begin{array}{l}\text { Olmesartan plus CCB } \\
\qquad\left(\mathrm{n}=1109^{*}\right)\end{array}$ & $\begin{array}{l}\text { Olmesartan plus diuretic } \\
\qquad\left(\mathrm{n}=1114^{*}\right)\end{array}$ & P-value & \\
\hline Age (years) & $69.7 \pm 2.9$ & $69.5 \pm 2.9$ & 0.13 & $78.8 \pm 2.7$ & $78.9 \pm 2.8$ & 0.49 & $<0.001$ \\
\hline Men & $809(55.4)$ & $819(56.1)$ & 0.74 & $514(46.3)$ & 511 (45.9) & 0.83 & $<0.001$ \\
\hline $\mathrm{SBP}(\mathrm{mm} \mathrm{Hg})$ & $158.1 \pm 12.7$ & $158.1 \pm 12.7$ & 0.97 & $157.8 \pm 12.8$ & $157.9 \pm 12.2$ & 0.98 & 0.47 \\
\hline DBP $(\mathrm{mm} \mathrm{Hg})$ & $88.7 \pm 10.5$ & $88.9 \pm 10.5$ & 0.61 & $84.9 \pm 10.8$ & $84.3 \pm 10.7$ & 0.16 & $<0.001$ \\
\hline Heart rate (b.p.m.) & $72.4 \pm 9.5$ & $72.6 \pm 9.1$ & 0.59 & $73.9 \pm 10.3$ & $73.3 \pm 9.6$ & 0.12 & $<0.001$ \\
\hline \multicolumn{8}{|c|}{ Cardiovascular risk factors } \\
\hline Dyslipidemia & $703(48.3)$ & $649(44.7)$ & 0.053 & $462(41.7)$ & $523(47.1)$ & 0.012 & 0.15 \\
\hline Diabetes mellitus & $400(27.4)$ & $388(26.6)$ & 0.65 & $284(25.6)$ & $290(26.0)$ & 0.85 & 0.36 \\
\hline Smoker & $417(28.8)$ & $437(30.2)$ & 0.44 & $224(20.4)$ & $211(19.1)$ & 0.49 & $<0.001$ \\
\hline \multicolumn{8}{|c|}{ Use of antihypertensive drugs at enrolment } \\
\hline ARB & $684(47.0)$ & $690(47.5)$ & 0.79 & $578(52.2)$ & $564(50.8)$ & 0.52 & 0.003 \\
\hline $\mathrm{CCB}$ & $519(35.7)$ & 478 (32.9) & 0.13 & $458(41.4)$ & 438 (39.5) & 0.36 & $<0.001$ \\
\hline$\beta$-Blockers & $132(9.1)$ & $88(6.1)$ & 0.003 & $99(8.9)$ & $103(9.3)$ & 0.82 & 0.051 \\
\hline Others & $178(12.2)$ & $193(13.3)$ & 0.4 & $154(13.9)$ & $179(16.1)$ & 0.15 & 0.022 \\
\hline
\end{tabular}

Abbreviations: ACE, angiotensin-converting enzyme; ARB, angiotensin receptor locker; CCB, calcium channel blocker; SBP, systolic blood pressure; y.o., years old.

Data are $n(\%)$ or mean \pm s.d.

*Excludes 16 patients for whom data were not collected after randomization (In the elderly age group, $n=1456$ in the olmesartan plus CCB group and $n=1452$ in the olmesartan plus diuretic group. In the very elderly age group, $n=1107$ in the olmesartan plus CCB group and $n=1110$ in the olmesartan plus diuretic group.).

At baseline, the mean age of the elderly age group was 69.6 years and the very elderly age group was 78.9 years. At baseline, there was no difference in systolic BP between the two groups and the very elderly age group had lower diastolic BP. The very elderly age group had higher rates of previous cardiovascular history of stroke and ischemic heart disease. Additionally, participants in the very elderly age group more often reported taking statins $(29.2 \%$ vs. $26.7 \%)$ and antiplatelet agents $(26.6 \%$ vs. $18.1 \%)$.

There were no significant differences in systolic BP and diastolic BP between the two combination groups in either age group at baseline (Table 1). The reduction in BP from baseline was similar between the two treatment groups in both age groups over the course of the trial. There was no significant difference in mean systolic BP or diastolic BP at each visit between the two treatment groups except for a few followup points, differences being within $1.8 \mathrm{~mm} \mathrm{Hg}$. At the end of the treatment phase (36 months), average BPs were 133.4 \pm 12.5/74.6 \pm 9.6 and $132.5 \pm 13.2 / 74.3 \pm 9.5 \mathrm{~mm} \mathrm{Hg} \quad(P=0.27$ for systolic BP, $P=1.0$ for diastolic BP) in the olmesartan plus CCB group and olmesartan plus diuretic group, respectively, in the elderly age group and 132.2 $\pm 12.7 / 71.3 \pm 9.9$ and $133.3 \pm 14.0 / 72.3 \pm 10.1 \mathrm{~mm} \mathrm{Hg}$ $(P=0.60$ for systolic BP, $P=0.067$ for diastolic BP) in the very elderly age group. Mean heart rate was $69.6 \pm 10.9$ and $70.0 \pm 11.4$ b.p. m. $(P=1.0)$, olmesartan plus CCB group and olmesartan plus diuretic group, respectively, in the elderly age group and $69.8 \pm 11.4$ and $71.2 \pm 12.1$ b.p.m. $(P=0.035)$ in the very elderly age group. Heart rates appeared to be slightly greater in the olmesartan plus diuretic group.

\section{Cardiovascular outcomes}

The incidence rate of the primary cardiovascular composite end point in the very elderly age group was higher than in the elderly age group (21.0 vs. 12.7 per 1000 person-years, $P<0.001$ ). The hard end point (cardiovascular death, non-fatal stroke and non-fatal myocardial infarction) in the very elderly age group was also higher than in the elderly age group (13.7 vs. 7.7 per 1000 person-years, $P<0.001)$. Figure 2 shows the HRs of the primary cardiovascular composite end point and the secondary end points in the olmesartan plus $\mathrm{CCB}$ to the olmesartan plus diuretic group in the two age groups. 


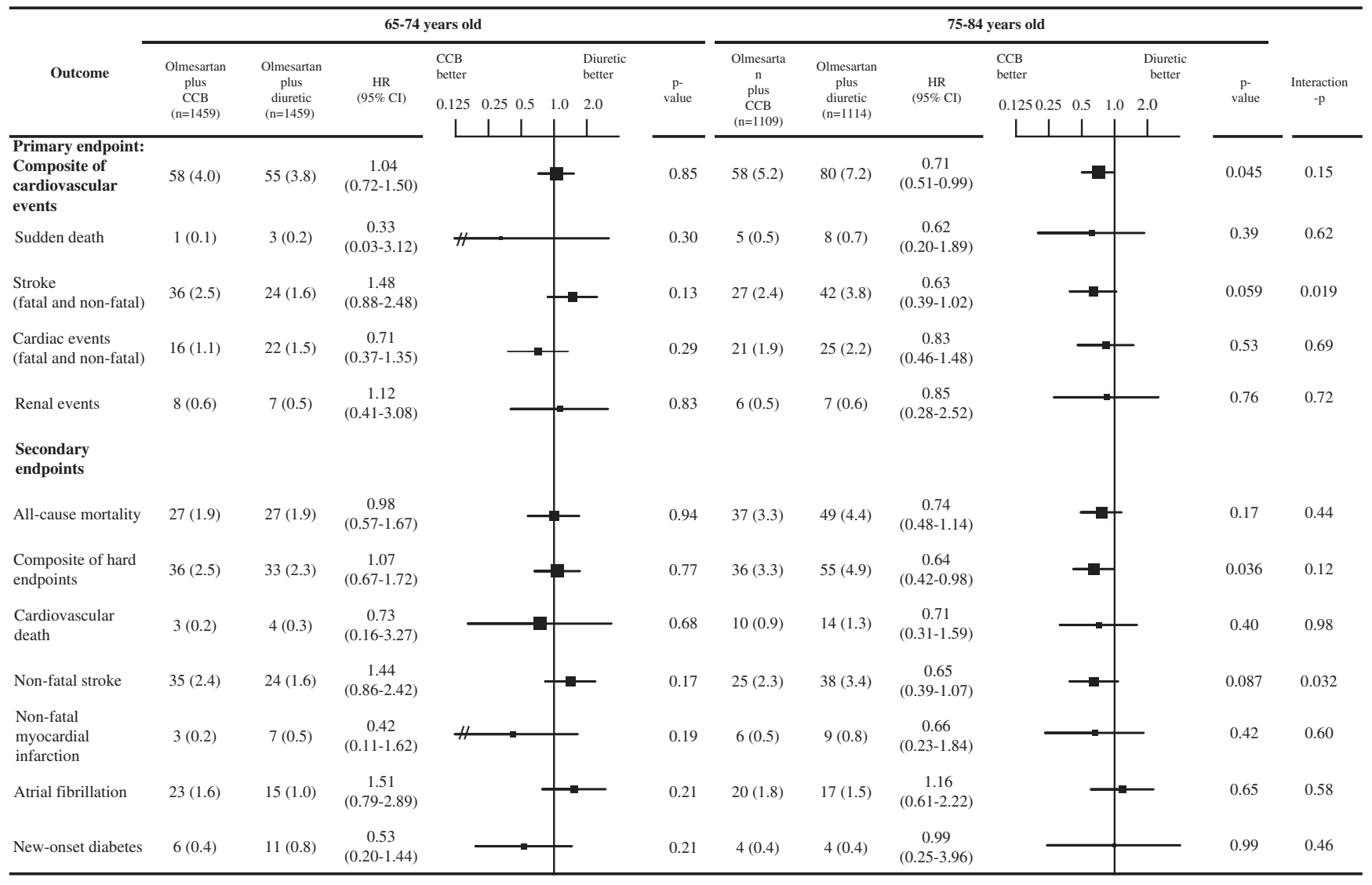

Figure 2 Incidence rates and hazard ratios (HRs) for primary cardiovascular composite end point and secondary end points: cardiovascular hard end points, fatal and non-fatal stroke including transient ischemic attack (TIA), all-cause mortality and new-onset diabetes in the two age groups and two treatment groups. Cardiovascular hard composite end points consisted of cardiovascular death, non-fatal myocardial infarction and non-fatal stroke excluding TIA. The HRs and 95\% confidence intervals (Cls) were determined using a stratified Cox proportional hazards model taking into account sex, age and baseline cardiovascular disease. The $P$-values were derived from a log-rank test, stratified by sex, age and baseline cardiovascular disease. Some results in this figure (line 3 , incidences of stroke) have already been reported. ${ }^{8}$ ARB, angiotensin receptor blocker; CCB, calcium channel blocker.

Figures $3 \mathrm{a}$ and $\mathrm{b}$ show Kaplan-Meier curves of the primary end point, composite of hard end points, stroke (fatal and non-fatal) and cardiac events (fatal and non-fatal) of each treatment group in the two age groups.

Compared with the olmesartan plus diuretic group, the incidences of primary end point and composite of hard end points were 29 to $36 \%$ lower as relative risk reduction in the olmesartan plus CCB group in the very elderly age group (HR, $0.71 ; 95 \%$ confidence interval, $0.51-$ 0.99 for primary end point, and $0.64,0.42-0.98$ for composite of hard end points); however, the interaction- $P$ values between the age groups did not reach statistical significance (interaction- $P=0.15$ for primary end point and interaction- $P=0.12$ for hard end point). Incidences of stroke (fatal and non-fatal) were marginally lower in the olmesartan plus CCB group than in the olmesartan plus diuretic group in the very elderly age group. Significant interactions between the patient's age and treatment were found in both stroke (fatal and non-fatal) and non-fatal stroke (interaction- $P, 0.019$ and 0.032, respectively). The HRs for these two end points were in the opposite directions with reference to 1.0 between the elderly age group and the very elderly age group; however, HRs of total stroke and non-fatal stroke were not significantly different in the elderly age group. No other significant interaction effects between age and treatment were found in other end points.

\section{Safety and tolerability}

Table 2 shows the adverse events reported and withdrawal rates. The proportion of patients with any adverse event and the withdrawal rate (including withdrawals due to drug-related SAE) were higher in the olmesartan plus diuretic group than in the olmesartan plus CCB group in both age groups. Drug-related SAEs were more frequent in the olmesartan plus diuretic group in the elderly age group.

Overall, abnormalities of laboratory data were more frequent in the olmesartan plus diuretic group than in the olmesartan plus CCB group in both age groups (Table 3). Hyperuricemia was more frequent in the olmesartan plus diuretic group than in the olmesartan plus CCB group in both age groups. Incidences of hyperkalemia were very low but significantly higher in the very elderly group than in the elderly group; however, there were no significant differences between two treatment groups in either age group. There were more cases with increased serum creatinine in the olmesartan plus CCB group in the very elderly group; however, the incidence was also very low (Table 3 ).

\section{DISCUSSION}

The Japanese Society of Hypertension Guidelines for the Management of Hypertension (JSH 2014) recommends combination therapy of any two drugs among four choices (CCB, ARB, angiotensin-converting enzyme inhibitor and diuretic) except $A R B$ plus angiotensin- 
a

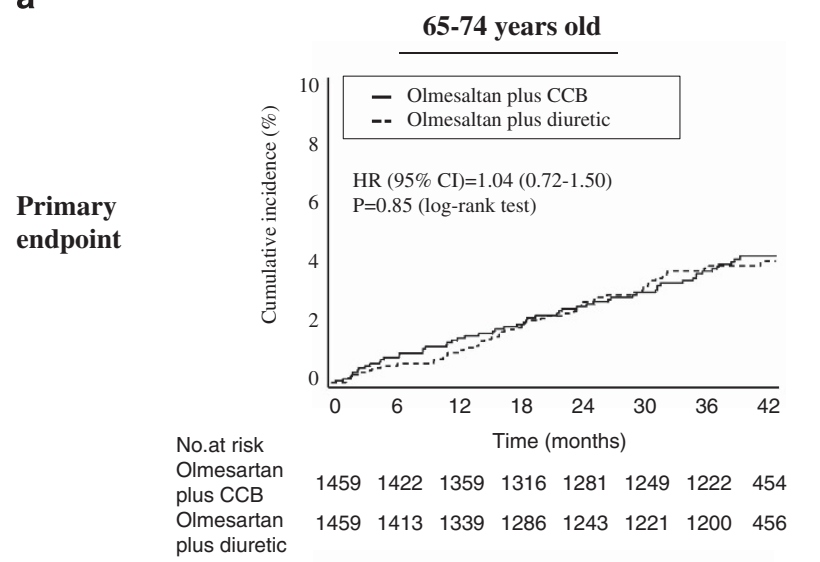

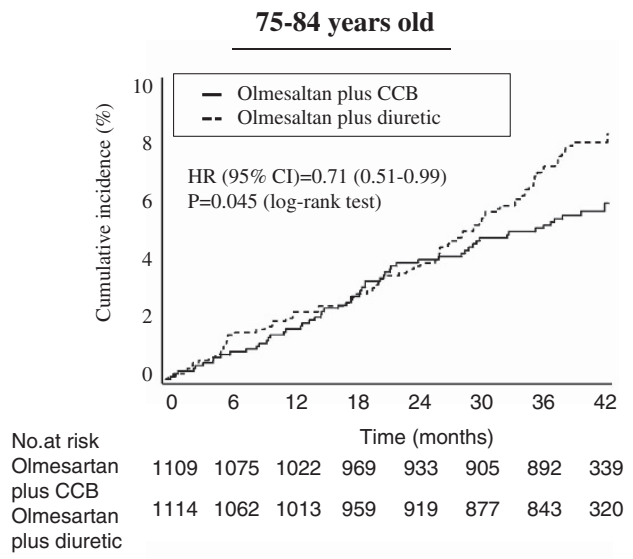
plus diuretic
Composite of hard endpoints

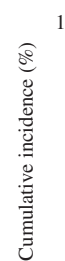

$\mathrm{HR}(95 \% \mathrm{CI})=1.07(0.67-1.72)$

$\mathrm{P}=0.77$ (log-rank test)

No.at risk

Olmesartan

plus CCB

Olmesartan

plus diuretic

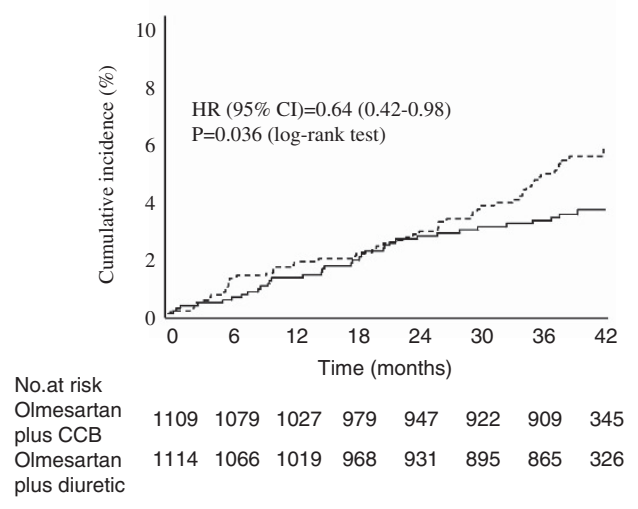

Olmesartan

\section{b}

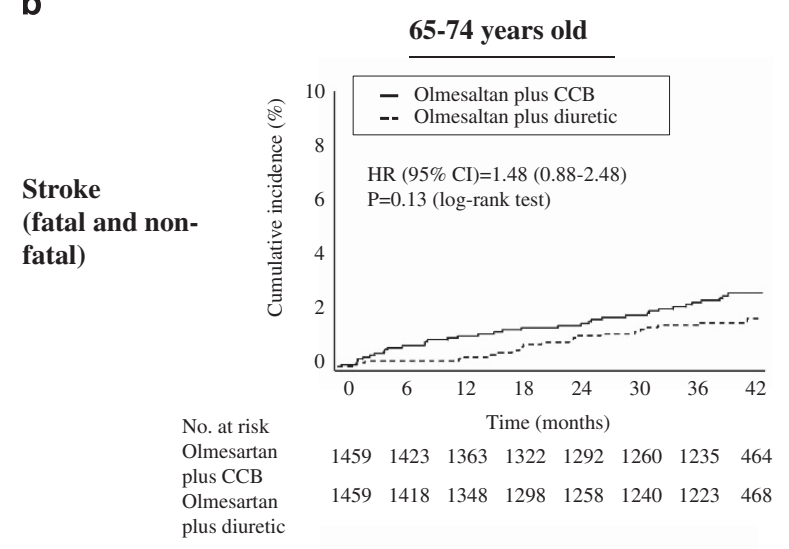

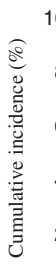

No. at risk Olmesartan plus $\mathrm{CCB}$ Olmesartan plus diuretic

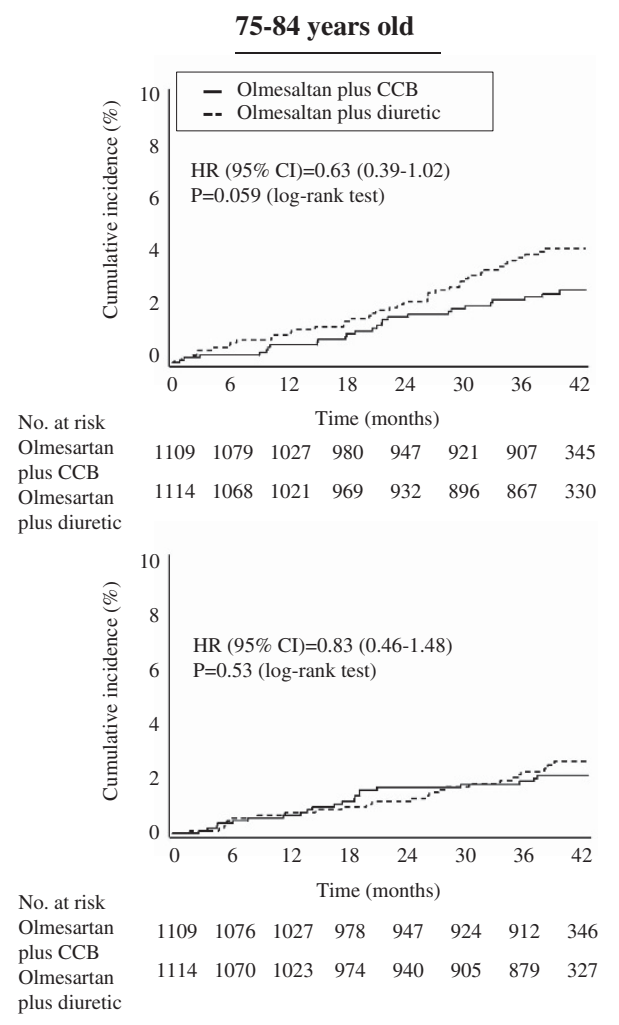

Figure 3 (a) Kaplan-Meier curves for the primary composite end point and composite of hard end points of the two treatment groups in both age groups. (b) Kaplan-Meier curves for stroke (fatal and non-fatal) and cardiac events (fatal and non-fatal) of the two treatment groups in both age groups. 
Age group (y.o.)

\begin{tabular}{|c|c|c|c|c|c|c|c|}
\hline & \multicolumn{3}{|c|}{$65-74$ y.o. } & \multicolumn{3}{|c|}{$75-84$ у.о. } & \multirow{2}{*}{$\begin{array}{c}\text { 65-74 vs. } 75-84 \\
\text { y.o. } \\
\text { P-value }\end{array}$} \\
\hline & Olmesartan plus $C C B$ & $\begin{array}{c}\text { Olmesartan plus } \\
\text { diuretic }\end{array}$ & P-value & Olmesartan plus $C C B$ & $\begin{array}{c}\text { Olmesartan plus } \\
\text { diuretic }\end{array}$ & P-value & \\
\hline Withdrawal rate & $290(20.2)$ & $444(31.2)$ & $<0.001$ & $231(21.4)$ & 366 (33.9) & $<0.001$ & 0.14 \\
\hline Withdrawal due to SAE & $31(2.1)$ & 57 (3.9) & 0.007 & $46(4.2)$ & $74(6.6)$ & 0.011 & $<0.001$ \\
\hline $\begin{array}{l}\text { Withdrawal due to drug-related } \\
\text { SAE }\end{array}$ & $2(0.1)$ & $9(0.6)$ & 0.065 & $3(0.3)$ & $7(0.6)$ & 0.34 & 0.83 \\
\hline Any adverse event & $343(23.5)$ & 395 (27.1) & 0.03 & $307(27.7)$ & 354 (31.7) & 0.037 & $<0.001$ \\
\hline SAE & $96(6.6)$ & $118(8.1)$ & 0.14 & $115(10.4)$ & $135(12.1)$ & 0.2 & $<0.001$ \\
\hline Drug-related SAE & $3(0.2)$ & $13(0.9)$ & 0.021 & $6(0.5)$ & $9(0.8)$ & 0.61 & 0.59 \\
\hline
\end{tabular}

Abbreviations: CCB, calcium channel blocker; SAE, serious adverse event; y.o., years old.

Data are $n(\%)$.

Table 3 Incidence of laboratory data abnormality

Age group (y.o.)

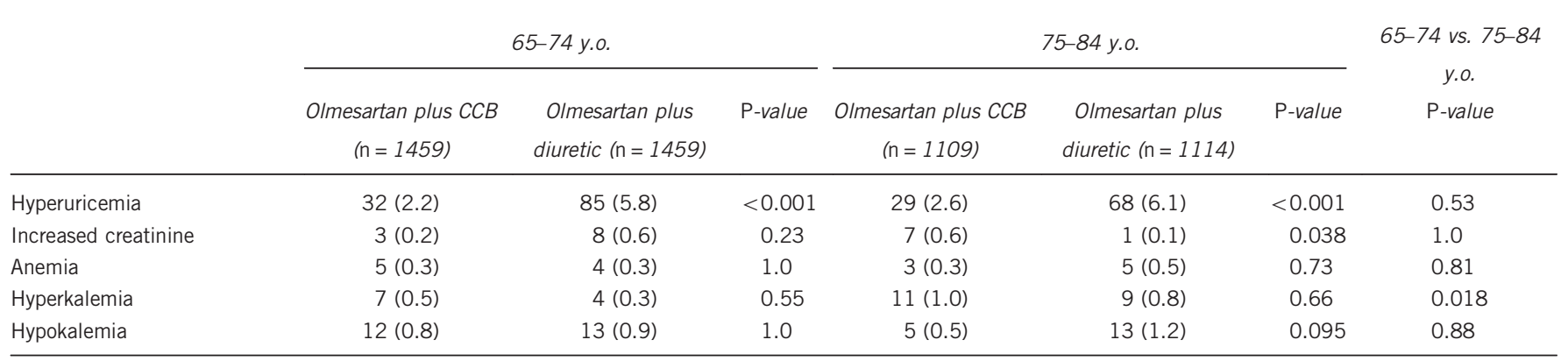

Abbreviations: CCB, calcium channel blocker; y.o., years old.

Data are $n(\%)$.

converting enzyme inhibitor in hypertensive patients whose BP control was insufficient with monotherapy. ${ }^{3}$ The American Society of Hypertension lists $\mathrm{CCB}$ with $\mathrm{ARB}$ as the preferred combination therapy, and $\mathrm{CCB}$ with diuretics as an acceptable combination therapy. ${ }^{9}$ However, these recommendations have not been proven by clinical outcome studies. ACCOMPLISH showed the superiority of the combination of the renin-angiotensin inhibitor, benazepril and $\mathrm{CCB}$ over the combination of the renin-angiotensin inhibitor and a diuretic in high-risk hypertensive patients with a mean age of 68.4 y.o. ${ }^{5}$ The findings of the COPE trial conducted in Japan showed that combinations of $\mathrm{CCB}$, benidipine with either thiazide, $\mathrm{ARB}$ and $\beta$-blocker therapy were equally effective in preventing cardiovascular events; however, the benidipine-thiazide group had a significantly reduced incidence of stroke, ${ }^{5}$ particularly in the elderly hypertensive patients aged 65 years and older. ${ }^{10}$

The principal results of the COLM trial are that there was no remarkable difference in the reduction of cardiovascular risk between the two treatment regimens of $\mathrm{ARB}$, olmesartan plus $\mathrm{CCB}$ and olmesartan plus diuretic for the treatment of hypertension in the elderly; however, the safety and tolerability profile showed some preference for olmesartan plus $\mathrm{CCB} .{ }^{8}$ In the previous report, we have already suggested that in patients aged 75 years and older the incidence of stroke was lower in the combination of olmesartan plus CCB than in the combination of olmesartan plus diuretic. ${ }^{8}$ In the present study, we further examined the results of the COLM trial according to prespecified subgroup analysis by age.

HRs of the olmesartan plus CCB group to the olmesartan plus diuretic group were $<1.0$ in the primary end point (cardiovascular mortality and morbidity) and hard end point (cardiovascular mortality, non-fatal stroke and non-fatal myocardial infarction) in the very elderly age group. The incidence of total stroke and non-fatal stroke was marginally lower in the olmesartan plus CCB group than in the olmesartan plus diuretic group in the very elderly age group, and the interaction- $P(0.019)$ was significant. Safety and tolerability profiles showed that olmesartan plus CCB combination was preferable to olmesartan plus diuretic combination in both age groups. These findings suggest that, for preventing cardiovascular events, stroke in particular, ARB plus CCB combination may be more effective for the treatment of hypertension in the elderly, particularly in those aged 75 years and older.

It has been reported that CCBs are favorable for the prevention of stroke compared with regimens based on diuretics or $\beta$-blockers. ${ }^{11,12}$ However, it is well known that the risk of stroke decreases with BP reduction rather than with a specific class of drugs. ${ }^{13,14}$ In the present subgroup analysis of the COLM trial, we observed a greater effect on the prevention of stroke in the combination of olmesartan plus $\mathrm{CCB}$ group compared with the combination of olmesartan plus diuretic group despite a similar reduction in BP between the two treatment groups in the very elderly group. Mechanisms behind the superiority 
of ARB plus CCB combination on stroke prevention in the elderly patients are unknown and could be a chance finding owing to small sample size. It is unlikely that the cause of interaction between the two age groups was related to the dosage and characteristics of the study drug combination because those were almost identical between the two age groups and between the two treatment groups in each age group (data not shown). Matsui et al. ${ }^{15}$ reported that central aortic $\mathrm{BP}$, pulse wave velocity and augmentation index were improved more in hypertensive patients treated with olmesartan plus CCB than in patients treated with olmesartan plus diuretic. These authors also reported that day-by-day variability of home BP was reduced more in the olmesartan-CCB-treated group compared with that in the olmesartan plus diuretic group. ${ }^{16}$ These findings may partially explain the present results, although the reason for the relatively selective benefit for the very elderly group is unknown. Webb et al. ${ }^{17}$ have shown that $\mathrm{CCB}$ reduced the visit-to-visit variability of $\mathrm{BP}$ more than diuretic in their meta-analysis. Further analysis, including visit-to-visit variability in the COLM trial, is required to explain the present results.

The mean heart rate at the end of the trial in the olmesartan plus diuretic group was significantly greater than in the olmesartan plus $\mathrm{CCB}$ group in the very elderly group. This might be a possible underlying mechanism because it is well known that heart rate is an independent risk factor for cardiovascular events. ${ }^{18}$

The safety and tolerability profile showed that there were more adverse events and withdrawals from the trial in the olmesartan plus diuretic combination therapy group than in the olmesartan plus CCB therapy group in both age groups as observed in the whole study population. ${ }^{8}$ Therefore, there are no specific concerns with respect to age in safety and tolerability in choosing for better combinations. An ARB and $\mathrm{CCB}$ combination may have some benefit in terms of safety and tolerability compared with ARB and diuretic combination in both age groups. Further large-scale trials are required to determine the optimal combinations to treat elderly hypertensive patients.

\section{Study limitations}

First, we adopted the PROBE design, so the non-blinded treatment allocation could have influenced the attitude of investigators toward compliance with the study. However, because BP reduction was similar in both groups, it is unlikely that some investigators biased the main outcomes of this study. Second, because the sample size of this subgroup analysis was relatively small, the optimal combination therapy for elderly hypertensive patients should be investigated in a future trial with a larger sample size and a longer period. Finally, as the enrolled patients were only Japanese, the results may not be generalized to other populations.

In conclusion, $\mathrm{ARB}$ combined with $\mathrm{CCB}$ may be preferable to ARB combined with diuretic regarding prevention of cardiovascular events, particularly stroke, in hypertensive patients aged $75-84$ years. The ARB plus CCB combination may have some benefit in safety and tolerability compared with the ARB plus diuretic combination in both 65-74 and 75-84 y.o. age groups.

\section{CONFLICT OF INTEREST}

All authors report receiving lecture fees and/or research grants from various pharmaceutical companies in Japan, including Daiichi Sankyo.

\section{ACKNOWLEDGEMENTS}

We thank the collaborators and members of the COLM study group. The present study was funded by Japan Heart Foundation. This study was endorsed by the Japanese Society of Hypertension. Some of the findings reported in the present study were presented in abstract form at the Joint Meeting ESH-ISH Hypertension Athens 2014 on 14 June 2014.

1 Beckett NS, Peters R, Fletcher AE, Staessen JA, Liu L, Dumitrascu D, Stoyanovsky V, Antikainen RL, Nikitin Y, Anderson C, Belhani A, Forette F, Rajkumar C, Thijs L, Banya W, Bulpitt CJ, HYVET Study Group. Treatment of hypertension in patients 80 years of age or older. New Engl J Med 2008; 358: 1887-1898.

2 Mancia G, Fagard R, Narkiewicz K, Redon J, Zanchetti A, Bohm M, Christiaens T, Cifkova R, De Backer G, Dominiczak A, Galderrisi M, Grobbee D, Jaarsma T, Kirchhof P, Kjeldsen SE, Laurent $\mathrm{S}$, Manolis AJ, Nilsson PM, Ruilope LM, Schmieder RE, Simes PA, Sleight P, Viigimaa M, Waeber B, Zannad F. ESH/ESC Guidelines for the management of arterial hypertension: the Task Force for the management of arterial hypertension of the European Society of Hypertension (ESH) and of the European Society of Cardiology (ESC). J Hypertens 2013; 31: 1281-1357.

3 Shimamoto K, Ando K, Fujita T, Hasebe N, Higaki J, Horiuchi M, Imai Y, Imaizumi T, Ishimitsu $\mathrm{T}$, Ito I, Ito $\mathrm{S}$, Itoh $\mathrm{H}$, Iwao $\mathrm{H}$, Kai $\mathrm{H}$, Kario $\mathrm{K}$, Kashihara $\mathrm{N}$, Kawano $\mathrm{Y}$, Kim-Mitsuyama S, Kimura G, Kohara K, Komuro I, Kumagai H, Matsuura H, Miura K, Morishita R, Naruse M, Node K, Ohya Y, Rakugi H, Saito I, Saitoh S, Shimada K, Shimosawa T, Suzuki H, Tamura K, Takahashi N, Tsuchihashi T, Uchiyama M, Ueda S, Umemura S on behalf of The Japanese Society of Hypertension Committee for Guidelines for the Management of Hypertension. The Japanese Society of Hypertension Guidelines for the Management of Hypertension (JSH 2014). Hypertens Res 2014: 37: 253-392.

4 James PA, Oparil S, Carter BL, Cushman WC, Dennison-Himmelfarb C, Handler J, Lackland DT, LeFevre ML, MacKenzie TD, Ogedegre O, Smith SC Jr, Svetkey LP, Taler SJ, Townsend RR, Wright JT, Narva AS, Ortiz E. 2014 Evidence-based guideline for management of high blood pressure in adults. Repaot from the panel members appointed to the Eighth Joint National Committee (JNC 8). JAMA 2014; 311: 507-520.

5 Jamerson K, Weber MA, Bakris GL, Dahlof B, Pitt B, Shi V, Heste A, Gupte J, Gatlin M, Velazquez EJ. ACCOMPLISH Trial investigators. Benazepril plus amlodipine or hydrochrolothiazide for hypertension in high-risk patients. New Engl J Med 2008; 369: 2417-2428

6 Matsuzaki M, Ogihara T, Umemoto S, Rakugi H, Matsuoka H, Shimada K, Abe K, Suzuki N, Eto T, Higaki J, Ito S, Kamiya A, Kikuchi K, Suzuki H, Tei C, Ohashi Y Saruta T. Combination Therapy of Hypertension to Prevent Cardiovascular Events Trial Group. Prevention of cardiovascular events with calcium channel blocker-based combination therapies in patients with hypertension: a randomized controlled trial. J Hypertens 2011; 29: 1649-1659.

7 Ogihara $T$, Saruta $T$, Rakugi $H$, Shimamoto $K$, Ito $S$, Matsuoka $H$, Horiuchi $M$, Imaizumi T, Takishita S, Higaki J, Katayama S, Saito I, Shimada K on behalf of the COLM study investigators. Rationale, study design and implementation of the COLM study: the Combination of OLmesartan and calcium channel blocker or diuretic in high-risk elderly hypertensive patients. Hypertens Res 2009; 32 : 163-167.

8 Ogihara T, Saruta T, Rakugi H, Saito I, Shimamoto K, Matsuoka H, Shimada K, Ito S, Horiuchi M, Imaizumi T, Takishita S, Higaki J, Katayama S, Kimura G, Umemura S, Ura N, Hayashi K, Odawara M, Tanahahi N, Ishimitsu T, Kashihara N, Morita S, Teramukai S for the COLM Investigators. Combinations of olmesartan and a calcium channel blocker or adiuretic in elderly hypertensive patients: a randomized, controlled trial. J. Hypertens 2014; 32: 2054-2063.

9 Gradman AH, Basile JN, Carter BL, Bakris GL. American Society of Hypertension Writing Group. Combination therapy in hypertension. J Am Soc Hypertens 2010; 4: 42-50.

10 Ogihara T, Matsuzaki M, Umemoto S, Rakugi H, Matsuoka H, Shimada K, Higaki J, Ito S, Kamiya A, Suzuki H, Ohashi Y, Shimamoto K, Saruta T for the Combination Therapy of Hypertension to Prevent Cardiovascular Events Trial Group. Combination therapy for hypertension in the elderly: a sub-analysis of the Combonation THerapy to Prevent Cardiovascular Events (COPE) Trial. Hypertens Res 2012; 34: 441-448.

11 Collier DJ, Poulter NR, Dahlof B, Sever PS, Wedel H, Buch J, Caulfield MJ, ASCOT Investigators. Impact of amlodipine-based therapy among older and younger patients in the Anglo-Scandinavian Cardiac Outcomes Trial-Blood Pressure Lowering Arm (ASCOT-BPLA). J Hypertens 2011; 29: 583-591.

12 Turnbull FBlood Pressure Lowering Treatment Trialists' Collaboration. Effects of different blood-pressure-lowering regimens on major cardiovascular events: results of prospectively-designed overviews of randomised trials. Lancet 2003; 362: 1527-1535.

13 ALLHAT Officers and Coordinators for the ALLHAT Collaborative Research Group. The Antihypertensive and Lipid-Lowering Treatment to Prevent Heart Attack Trial. Major outcomes in high-risk hypertensive patients randomized to angiotensin-converting enzyme inhibitor or calcium channel blocker vs. diuretic: The Antihypertensive and Lipid-Lowering Treatment to Prevent Heart Attack Trial (ALLHAT). JAMA 2002; 288: 2981-2997.

14 Blood Pressure Lowering Treatment Trialists' Collaboration, Turnbull F, Neal B, Ninomiya T, Algert C, Arima H, Barzi F, Bulpitt C, Chalmers J, Fagard R, Gleason A, Heritier S, Li N, Perkovic V, Woodward M, MacMahon S. Effects 
of different regimens to lower blood pressure on major cardiovascular events in older and younger adults: meta-analysis of randomised trials. BMJ 2008; 336: $1121-1123$.

15 Matsui Y, Eguchi K, O'Rourke MF, Ishikawa J, Miyashita H, Shimada K, Kario K. Differentia effects between a calcium channel blocker and diuretic when used in combination with angiotensinll receptor blocker on central aortic pressure in hypertensive patients. Hypertension 2009; 54: 716-723.

16 Matsui Y, O`Rourke MF, Hoshide S, Matsui Y, Shimada K, Kario K. Combined effect of angiotensin II receptor blocker and either a calcium channel blocker or diuretic on day-by-day variability of home blood pressure: the Japan combined treatment with olmesartan and a calcium channel blocker versus olmesartan and diuretics randomized efficacy study. Hypertension 2012; 59: 1132-1138.

17 Webb AJ, Fischer U, Mehta Z, Rothwell PM. Effects of antihypertensive-drug class on interindividual variation in blood pressure and risk of stroke: a systematic review and meta-analysis. Lancet 2010; 375: 906-915.
18 Ho JE, Larson MG, Ghorbani A, Chen S, Coglianese EE, Vasan RS, Wang TJ. Long-term cardiovascular risks associated with an elevated heart rate: the Framingham Heart Study. J Am Heart Assoc 2014; 3: e000668.

(c) (1) $(9)$ This work is licensed under a Creative Commons Attribution-NonCommercial-NoDerivs 3.0 Unported License. The images or other third party material in this article are included in the article's Creative Commons license, unless indicated otherwise in the credit line; if the material is not included under the Creative Commons license, users will need to obtain permission from the license holder to reproduce the material. To view a copy of this license, visit http://creativecommons.org/licenses/by-nc-nd/3.0/ 